\title{
An ecological approach to personality : Psychological traits as drivers and consequences of active perception
}

\section{Satchell, Liam Paul}

2021-05

Satchell , L P , Kaaronen , R O \& Latzman , R D 2021, ' An ecological approach to personality : Psychological traits as drivers and consequences of active perception ' , Social and personality psychology compass , vol. 15 , no. 5 , e12595 . https://doi.org/10.1111/spc3.12595

http://hdl.handle.net/10138/330867

https://doi.org/10.1111/spc3.12595

cc_by_nc

publishedVersion

Downloaded from Helda, University of Helsinki institutional repository.

This is an electronic reprint of the original article.

This reprint may differ from the original in pagination and typographic detail.

Please cite the original version. 


\title{
An ecological approach to personality: Psychological traits as drivers and consequences of active perception
}

\author{
Liam Paul Satchell ${ }^{1}$ (1) | Roope Oskari Kaaronen ${ }^{2}$ (1) | \\ Robert D. Latzman ${ }^{3}$
}

${ }^{1}$ Department of Psychology, University of Winchester, Winchester, UK

${ }^{2}$ Faculty of Social Sciences, Helsinki Institute of Sustainability Science, University of

Helsinki, Helsinki, Finland

${ }^{3}$ Department of Psychology, Georgia State University, Atlanta, Georgia, USA

\section{Correspondence}

Liam Paul Satchell, Department of Psychology, University of Winchester, Sparkford Road, Winchester, Hampshire, SO22 4NR, UK.

Email: liam.satchell@winchester.ac.uk

\begin{abstract}
The ecological approach to perception highlights how organisms engage in active perception and that the environment is understood relative to an individual's physical traits. Personality research draws attention to the variability in psychological traits that affect the way individuals differentially explore and anticipate the world. The current paper identifies compatibilities in these fields and suggests that personality both initiates and perpetuates the manner with which individuals engage in active perception. Personality traits both drive and limit perceptual refinement of the world and also lead to the construction of niches to suit personality. Here, we explore the benefits for considering individual differences in perception and active perception in regards to personality theory, comparative psychology, mental health, research methodology, and intervention. We conclude by encouraging both ecological and personality research to consider the benefits of understanding personality traits as mechanisms for initiating or constraining active perception.
\end{abstract}

This is an open access article under the terms of the Creative Commons Attribution-NonCommercial License, which permits use, distribution and reproduction in any medium, provided the original work is properly cited and is not used for commercial purposes. (c) 2021 The Authors. Social and Personality Psychology Compass published by John Wiley \& Sons Ltd. 


\section{1 | INTRODUCTION}

This paper attempts to bridge two literatures which typically do not interact with each other: ecological psychology and personality science. We highlight the implications of (i) perception of "affordances" and behaviorperception coupling for personality science and (ii) variation in perception of "affordances" due to differences in psychological traits for ecological psychology. We describe the ecological approach to psychology and its benefits in more detail later, but it is our position that this mutualist model of sensemaking is an important theoretical framework for personality psychology. It is our hope that the current paper will provide a catalyst for a theoretical discussion about what traits mean for individual differences in behavior emerging in contexts. While other models have tried to identify the role of vision and senses in personality psychology (to mixed success; Grzeczkowski et al., 2017), the ecological approach lends itself to a much broader conceptual rethinking about sensemaking and how environments solicit behavior from individuals. An ecological approach is about the understanding of individual's perceived behavioral opportunities and gives important focus on what the environment might offer an individual in a place. It follows that the measurement of personality should focus on the understanding of opportunities for behavior in a particular context. We describe how understanding personality assessment from a behavioral perspective broadens the way in which we might discuss and measure traits, up to and including more ready inclusion of cross-species findings. Reconsidering personality science from an ecological perspective has practical and applied implications. This can include focusing on how personality change and development affect the ways in which individuals create, seek, and maintain contexts around them, with implications for mental well-being. We discuss these opportunities for theoretical gain to draw more attention to the possibilities of this work and hope to spur a conversation between these fields. But first, to best set the scene for this under-explored discussion and highlight the uniqueness of the ecological approach for personality psychologists, we will start with an illustration of the traditional ecological approach to perception.

\section{2 | AN ILLUSTRATION}

Consider a high platform that has a safety rail running around the outside. This safety rail is high enough that it is above the typical adult's waist. An adult on the platform might thus perceive the environment as safer due to the presence of the railing. However, a child, too short to benefit from this adult-height railing, will not have the same perception of the context as the adult. Their perception, based on the physics of the world, has a different meaning for them based on their height. In this context, the individual's physical traits (their height) have changed the way they perceive the same environment.

There has been much research and theory into the role of physical traits in perception (discussed later), however, what has received surprisingly less attention is the role of psychological traits (personality) in the activity of perception. For example, the safety rail described above has different perceptual value for an adult with the same appropriate physical traits for the rail, but different psychological traits, such as an elevated threat sensitivity disposition. They will perceive the situation as being more dangerous than someone of similar physical traits. These individual-level differences, expressed through consistent patterns of perception and behavior can be termed personality traits. In this paper, we set out the case for more dialog between scholars who study individual differences, and those who study the ecological approach to perception. A consideration of the nature of perception-action coupling has the potential to develop theory, research, and application of individual differences in dynamic everyday settings. Essential to this conversation is the notion that traits drive behavior, which shape perception, which subsequently drive future behavior. 


\section{3 | PERSONALITY}

In this paper, we discuss individual differences in broad terms. There are many theories of personality which offer varying nuanced explanations as to how individual differences manifest. The arguments we make here do not need to be anchored to any one particular framework, as it is possible for our discussion to relate to many preferred models of readers. We consider personality traits to be the generally consistent elements of thought, behavior, and affect displayed by an organism across contexts (Kenrick \& Funder, 1988). These traits have a consistent driving force on an organism's behaviors and thoughts; however, particular expressions of behavior will vary depending on particular situations (Fleeson, 2004). There is sufficient research to claim that personality traits have biological drivers (DeYoung, 2010) and that traits can change over the lifespan (Graham et al., 2020). Traits can be the target of intervention and change in response to life events (Lüdtke et al., 2011; Magidson et al., 2014; Roberts et al., 2017). While traits cannot be directly observed-and there are measurement challenges to directly measuring traits be it through forced-choice self-report, introspection, informant reports, observation, biological measurement, etc.-the effects of personality traits on behavior are one of the most reliable and replicable fields of psychological study (Soto, 2019).

Personality models diverge in terms of their understanding of the nature and number of core factors that drive behavior. These often reflect methodological choices by theory proponents. As has been argued elsewhere, there are many competing "Big Trait" models, but they can be considered within a similar overall hierarchy, with differing levels of specificity around core traits (Markon, 2009). Most theories, across human and non-human animals, contain elements of higher-order factors pertinent to variability in how organisms "Approach" the world and in "Anxiousness" about potential threats (Gosling \& John, 1999; Latzman, Freeman, et al., 2015; Markon, 2009). In using these two broad trait names, we have specifically chosen terms not generally used as trait descriptors to maintain our broad discussion away from any one model. We do not advocate for these as new traits or to replace existing constructs which may have more nuance.

In the term "Approach," we reflect the broad individual difference in the intensity with which an organism interacts with, and seeks information from, the world. There are many examples of traits that fit into the broad Approach dimension in existing personality models such as Extraversion (Ashton \& Lee, 2009; McCrae \& Costa, 1987), the Behavioral Approach System (Corr, 2004), liveliness (Cattell, 1973), and positive emotionality (Tellegen, 1985). This broad construct is a staple of various human and animal frameworks of individual differences and appears to be largely homologous among various non-animal species (expanded below). Fundamentally, Approach explains variability in the extent to which individuals are driven to being active perception so as to satiate a "need-for-perception."

In referring to "Anxiousness," we describe the broad literature on individuals' tendency to perceive heightened risk in an ambiguously threatening environment (for an overview of commonalities in these traits, see Van den Bergh et al., 2020). This broad trait dimension reflects traits such as Neuroticism (McCrae \& Costa, 1987), Emotional Stability (in HEXACO; Ashton \& Lee, 2009, and 16PF; Cattell, 1973), the Behavioral Inhibition System (Corr, 2004), and Negative Emotionality (Tellegen, 1985). For example, in our high platform illustration above, while there was not necessarily an immediate threat, one adult perceived more risk than the other. This broad trait dimension has an important role for understanding psychological risks for developing various maladaptive behaviors-both when Anxiousness is a strong (Brandes \& Tackett, 2019) or a weak (Gomez \& Corr, 2010) driver of behavior.

\section{4 | THE ECOLOGICAL APPROACH}

Gibson's $(1966,1979)$ ecological approach to perception is a mutualist theory of sensemaking (Heft, 2001; Reed, 1996). This approach centers around two important ideas that give insight to broad ideas about making sense of the world. First, organisms perceive "affordances" for behavior. Gibson's model promotes a framing of 
sensemaking that is neither purely subjective nor purely objective, but perception is an activity in "subjectiveobjectivity." Organisms detect the (objective) world around them, and experience meaning relative for themselves and their behavior (subjectivity). An affordance is the behavioral potential of an environment for an organism. For instance, a railing "affords" support if it is of a proper height for a person. The "objectivity" of an affordance highlights that the sensory organs of an organism are fundamentally detecting physics. Light reflects off surfaces and this is the primary source of visual perception (Gibson, 1979). Physics becomes "information" when the sensory organs of an organism process the physical quality of the world in the context of the organism's traits. Typically, ecological psychologists consider the role that physical traits play in information creation, such as an individual's leg length affecting perceptions of stairs (Warren, 1984). In the opening example, the safety railing is not meaningfully a handrail for the child who is too short to make use of it. The physics of the railing is not different for the child or the adult, but the information is different. The information from various sources in an environment bundles together to offer "affordances" for a perceiver. Affordances are the opportunities for behavior which the environment solicits (Chemero, 2003), and they are holistic perceptions of the environment. For the less anxious adult in the starting example, the environment on the high ledge has affordances of "safe-to-be-on-ness" due to the information from the railing (and other unmentioned sources). The child perceives no such affordances as the collective information provides no security, due to the lack of a physical trait-suitable railing.

Second, Gibson encourages us to consider how perception and action are inseparable. A behavior is the result of perception which is, in turn, refined through behavior. The process of doing behavior creates more information from the world to be perceived. Despite the common (originating) focus on visual perception in ecological psychology, the idea of perception is much broader and has readily been applied to non-visual information. For example, behaviors to refine perception could be testing the strength of a frozen lake before perceiving it to have affordances of "walk-on-able-ness," an infant's use of tactile exploration to test the "crawl-on-able-ness" of an invisible surface (as studied in "visual cliff" experiments, see Gibson \& Walk, 1996), or smelling an unknown food to see if it has affordances of edibility. In these cases, naive visual evaluation is not enough to perceive the affordance, but perception motivates behavior to refine perception. It is notable how frustrating the inadvertent decoupling action and perception can be, illustrated by when a video chat or online activity "lags," and the action with the (digital) world does not react with the expected new sensory information at the expected speed. Similarly, the effects of many perceptually confusing visual illusions, such as those presented on 2D surfaces or from forced-static vantage points can be diminished through active perception (Kennedy et al., 1992). Gibson's recognition of the inseparability of perception and action is important for understanding perception and has implications for how individual differences in emergent behavior might shape differences in perceived experience. The role of (in)action with the world in forming perception has implications for how we might measure and study the experience of others (see more later).

Fundamentally, these two key theoretical elements separate the work of the ecological approach from other models of "perception" and expanded the idea of what an approach of sensemaking can mean for being a person in the world. This is a model that understands how an individual's presence in certain environments leads to behavior and how behavior is inseparable from sensemaking. With this understanding of how behavior emerges, we can next consider an ecological approach to individual differences.

\subsection{An ecological approach to individual differences}

The above two Gibsonian principles highlight the importance of (physical) traits for perceiving affordances and perception-behavior coupling. What is less considered in the ecological approach, is the role of psychological traits. If we are dispositionally inclined to engage with some behaviors more than others, this would affect how we perceive the world. For example, the person who is more Approach oriented, and driven to act with the world more, is the person who is more likely to experimentally try the sturdiness of the frozen lake. Similarly, the person who is 
higher on Anxiousness tendencies is the one who is less tempted to smell the unknown food in the first place, due to considering there to be more risk to engaging in behaviors to discover more information. In this framing, psychological traits are affecting how and when we explore for and exploit (make use of) information. A focus on individual differences in active perception has the benefit of allowing discussion between personality research and those who often study and model exploration-exploitation tradeoffs (see Mehlhorn et al., 2015), Dynamics of Action (see Revelle \& Condon, 2015), Approach-Avoidance motivations (Elliot, 2006) or motivation of individual biological sensitivities (Denissen \& Penke, 2008), whilst at the same expanding thinking around these models to be mutualist. Differentially active perceivers might be driven to more exploration or more exploitation based on pursuit (or avoidance) or information.

The principles of the ecological approach move the activity of perception from within an animals' mind to the dynamic process between the animal and the environment. In doing so, Gibson highlights Darwinian principles of how animals understand their immediate context through affordances and the lack thereof, known as "constraints" (Reed, 1996). Importantly, animals create their own niches through their behavior and continually redefine the constraints of a niche they find themselves in. For example, the lack of a safety rail in high places creates constraints on human activity, due to perceived risk. Therefore, through behavior, humans create niches more conductive for affordances, such as by building handrails (Norman, 1988; Reed, 1996). This is a process generally known as "niche construction" (Laland, 2017) and it is a dynamic process of refinement and adaptation over time. Again, environmental niche-based constraints have historically been discussed in terms of physical traits (the height of the safety railing); however, we can go further and consider the effect of an individual's personality traits (behavioral tendencies) on niche construction and maintenance. The individual who is less sociable is one who perceives constraints within an environment where there are many other people. Their personality affects the perception of affordances and constraints, which will solicit or prohibit behaviors, which will, in turn, lead to the discovery of different information. The individual might perceive that they are more welcome in a social context (and perceive affordances of "receptiveness") as they are drawing more attention from their peers, a product of their initiation of social behavior first. Whereas the individual who is less sociable might perceive more constraints in the interaction, as they are not the focus of attention. However, this is due to their less attention-gathering behavior in the first place, driven by their less sociable traits. Thus, the perception-action cycle, driven by traits, creates and maintains niches, which regulate information for the perceiver.

In summary, the ecological approach has primarily focused on the role of physical traits for defining the perception of affordances. However, psychological traits, as general drives for behavior, also have a role in the initiation of the behavior element of the perception-action coupling. Thus, there is a clear need to consider the role of personality in perception research. Moreover, the development and manifestation of personality traits can be considered as part of the ecological framework. There are many benefits to this closer integration, which have, to date, been largely unexplored (but see attempts to use ecological psychology to bridge personality and social psychology; Baron \& Boudreau, 1987). Below, we draw attention to the opportunities offered by this conversation between fields. First, the ecological approach allows for a broad, but also effective, discussion of the effects of interand intra-species variability in behavior (which we describe through a consideration of variance in Approach behavior). Second, the way that behavior, perception, and niche-construction are interlinked in the ecological approach is useful in understanding the development (and treatment) of cyclical maladaptive trait behavior (as affected by trait Anxiousness).

\section{2 | An ecological perspective on trait Approach}

Survival requires effective exploration and exploitation of the environment (Mehlhorn et al., 2015). A life of a complex organism is filled with alternative behaviors, such as continuing to feed in a place (exploit), or moving to search elsewhere (explore). Complex organisms are required to approach and explore their environment, and 
behave with it, to create suitable niches for living and to extract energy. This will involve activity to better perceive information about environmental sources of nutrition, shelter or through interaction with conspecifics. Active engagement with the world is essential to the ecological approach, and Gibson was firm in the assertion that "the observer who is awake and alert does not wait passively for stimuli to impinge upon [their] receptors" (1966, p. 32, see Costall, 2017). However, such information-seeking behavior is not uniform within a species, and there is evidence of individual differences in the extent to which an organism expresses these behaviors. In humans, this can be seen in research into specific traits such as "sensation seeking" (Zuckerman, 1994), "venturesomeness" (Eysenck \& Eysenck, 1978), "restlessness" (Klinteberg et al., 1990; Morris \& Warne, 2017), or broader domains such as the Behavioral Approach System (BAS; Corr, 2004) and Extraversion or Openness (de Vries et al., 2009). Given the ecological approach's firm basis in physical traits and biology for explaining perceived affordances, it should be noted that there is a wealth of research into the biology of sensation seeking (Zuckerman, 2005). In particular, traits associated with Approach can drive information seeking behavior based on individual differences in the biological arousal responses to environmental stimuli.

This has been explored experimentally using personality models such as the Gray-Eysenck (Gray, 1970) and Cattell (Matthews, 1987) models, where the Approach-oriented person finds themselves understimulated and needing more from the world. In much the same way, others who are more readily satiated with the information they are experiencing, behave towards the world less. This underlying need for more stimulation is an example of an individual difference in perception driving behavior which affects perception. Reinforcing the perceptual component of this relationship is research demonstrating that those who are more Approach-oriented experience a slower passage of time (Koswara et al., 2020; Rammsayer, 1997). In experiencing time slower, there is more room for information to be perceived. Similarly, an individual is able to discover more information from the environment, then more time to act and perceive will be experienced. A broader illustration of this process would be to consider how slow Internet loading times can be frustrating, an emotional reaction to the mismatch in the expected volume of information that can be experienced and what is being experienced. The personality component is how individuals perceive the amount of information to occur (time to frustration with slow loading times). Broadly, those inclined to trait Approach, may have the phenomenological experience of missed opportunity to get information, so the individual creates more stimulation to satiate themselves through their action.

Research into Approach traits has also highlighted how individuals can be information seeking from the environment in immediate (i.e., "Now BAS") or planful long-term (i.e., "Future BAS") manner (Satchell et al., 2018). The immediate-information sensation seeking behaviors have received a large amount of dedicated research due to the implications for many complex manifestations of the behavior, such as in criminal (Pratt \& Cullen, 2000), substance abuse (Hittner \& Swickert, 2006), and sexual (Bancroft et al., 2004) contexts. Similarly, planful approaches to seek information from the world can affect other complex behaviors, such as touristic behavior (Jani, 2014; Li \& Tsai, 2013) and willingness to relocate for work (Otto \& Dalbert, 2012). These are examples of how more nuanced refinement of specific types of Approach is possible (and desirable) but it is important to conceptualize these within a framework of perceptual refinement.

Conceptualizing traits, as expressions of variability in tendencies to seek and refine information from the world, allow for ready integration of comparative (non-human animal) approaches to individual differences. The consideration that perception is inseparable from the expression of (or lack of) behavior leads to the promotion of observational approaches to personality measurement. As others have argued, behavioral observation is a historically underused element of human personality research (Back \& Egloff, 2009; Furr, 2009), but this method offers opportunities to better understand consistency in active perceiver behavior across settings. Importantly, methodologies that do not rely solely on self-report can be more readily used across species to understand commonalities in personality. Such observation could focus on how individuals act towards novelty (where there is variability in exploration of affordances through action) or in their exploration of space. For example, in chimpanzees, Approach-oriented tendencies have been found to predict variation in active perception of a novel stimulus (human mannequin, Latzman, Freeman, et al., 2015). Approach towards novelty and exploration of space 
are currently used across many species to assess their individual differences, and it is possible to understand these behaviors in the ecological framework.

As Nagel famously demonstrated by asking "what is it like to be a bat?" (1974), it is difficult to understand the phenomenological experience of a species with greatly different physical traits to our own. However, through observation, we can identify familiar individual differences in how behavior-perception cycles differ within other species. There is insight to be gained by asking what it is to be like the Approach-oriented bat. This has been studied by Menzies et al. (2013), for example, who demonstrated that Little Brown Bats show variability in their tendencies to explore their environment through their locomotion and echolocation. The bats demonstrate recognizable individual differences in their affordance-refining behaviors. Approach-like tendencies have been observed in a variety of species; chimpanzees (Latzman et al., 2016, 2017), dogs (Piotti et al., 2018; Wright et al., 2012), cats (Bennett et al., 2017), birds (great tits, Exnerová et al., 2010; superb fairywrens, Jacques-Hamilton et al., 2017), rhinoceroses (Carlstead et al., 1999), octopuses (Sinn, Perrin, et al., 2001), and sharks (Finger et al., 2016). There is also evidence of intra-species variability in consistent Approach-like behavior in less frequently studied invertebrates (Kralj-Fišer \& Schuett, 2014), such as Old Field Jumping Spiders (Sweeney et al., 2013), Mustard Leaf Beetles (Tremmel \& Müller, 2013), Firebugs (Gyuris et al., 2012), and even Giant Sea Anemones (Hensley et al., 2012).

Many of the operationalization of Approach listed here are oriented around basic survival affordances. For example, there are consistent individual differences in how Dumpling Squid approach novel food sources, with variance in the number of touches, arm flower postures and grab movements they make (Sinn et al., 2008). These squid personality-driven behaviors affect their perception of affordances, much like the earlier example of a human smelling food to perceive edibility. Whilst organisms perceive fundamentally different affordances due their physicality and their medium of experiencing information (i.e., echolocation, electroreception, etc.), there is also variability within species not explained by physicality alone. Indeed, psychological traits, partly biological in origin, partly developed through perception-action cycles, are widely present throughout living species (Weiss, 2018). Therefore, ecological explanations of perception need to explain individual differences in the psychology of affordances.

This section has focused on how a broadly defined Approach trait can contribute to an understanding of individual differences in perception. Beyond physical traits, affordances can vary within a species and this is driven by base biological requirements, such as need for stimulation. The manifestation of complex individual differences, such as restlessness or venturesomeness, are the consequence of a need of an individual to create more information (due to a perceptual deficit) through acting with the world. Further, personality traits which explain variance in affordance-refinement, need not be bound to a particular species, reinforcing conversations about comparative approaches to personality.

\subsection{An ecological perspective on trait Anxiousness}

Distinct to the dispositional Approach behavior is Anxiousness. Whereas Approach traits explain variance in how environments are explored for affordances, Anxiousness traits describe the tendency to apprehensively appraise and cautiously initiative engagement with environments. As noted above, it is common to many personality models to have a trait describing sensitivity to potential risk in the environment as something distinct to Approach, such as Neuroticism, Emotional Stability, Behavioral Inhibition Systems, or Negative Emotionality. Many of these traits can be seen as being part of a broader "better safe than sorry", risk-averse, orientation toward the world (see Van den Bergh et al., 2020). Anxiousness traits shape perception and can be studied through cross-species observation, much like with the examples described in Approach traits above. Here, we focus on how Anxiousness traits maintain perceptual-poverty loops and niche construction in the ecological framework. It is important to note that whilst Anxiousness traits play a role in risk for psychopathology (Van den Bergh et al., 2020) and high anxiety is 
often considered maladaptive, there are benefits to this trait as well. The expression of the Anxiousness traits can be functional, such as encouraging more public-health compliant behavior in a global pandemic (Harper et al., 2020) or how those who are higher on Anxiousness traits have lower mortality due to accidents in longitudinal research (Lee et al., 2006). The widespread, or even normative, prevalence of Anxiousness traits is evidence of contextual functionality of this seemingly problematic trait.

Much like with Approach traits, Anxiousness traits can be considered as part of a sensemaking process, perhaps initiated by biological drives (i.e., neuroticism is highly heritable, Boomsma et al., 2018). A defining element of the broad spectrum of Anxiousness traits is the tendency to foresee risks in engaging in behavior. The expectation of potential harm will lead to behaviors (or lack thereof) which regulate exposure to ambiguous environments. From a perspective based in the ecological approach, the protective Anxiousness traits result in the maintenance of a poverty of information about the ambiguous context-albeit motivated by risk mitigation. There are contexts where information discovery could harm or even kill an organism, and the more Anxious individual considers this more often. As perception and action are inseparable, the restriction of behavior restricts sensemaking disincentivizing future behavior toward that context, and the cycle continues. An actor with limited Anxiousness traits might risk engaging with the high platform in the opening illustration, to better understand its safe-to-be-on-ness (their style and extent of that exploration would be affected by their Approach traits). In doing so, the more trait bold actor will better understand the affordances in that environment (for them). This is in contrast to the Anxious actor, who does not engage with the high platform in the first place and maintains a poverty of information about that place. The ecological approach helps understand how a "perceptual-poverty" loop like this is developed. This can lead to maladaptive behaviors or avoidance of opportunities to change an individual's own behavior.

Recent research supporting this model comes from phenomenological psychiatry, where De Haan et al. (2013) suggest that the experience of obsessive-compulsive disorder results in an impoverished or a distorted field of affordances. This, in turn, restricts the fields of affordances they explore. Complementary to this is the work in cultural evolution which draws attention to the "niche diversity hypothesis," which proposes that "a greater diversity of social and ecological niches elicits a broader range of multivariate behavioral profiles and, hence, lower trait covariance in a population" (Smaldino et al., 2019). These ideas draw particular attention to considering how an organism-environment relationship explains the selection and maintenance of opportunities for behavior in trait Anxiousness.

There is evidence that some Anxiousness traits are malleable (Sauer-Zavala et al., 2017) and suggest that these traits respond to therapeutic intervention. The process of therapy, whereby assumptions about the potential risks of an environment are often challenged, allows external intervention in the perceptual-poverty loop. This creates more drive for active perception in novel environments to be initiated, and the activity of information seeking should, in turn, refine perceptions of perceived risks. However, there is evidence that those with stronger initial Anxiousness traits are more resistant to change (Brown, 2007), suggesting that external, out-of-context intervention on this cycle is limited in the strongest cases. That being said, the understanding of behavior and perception as inseparable provides insight to those who wish to intervene on personality, especially in the context of Anxiousness.

Gibson's ecological approach is a mutualist theory whereby organisms shape the environments that shape organisms' behavior. Thus, this approach to discussing trait Anxiousness moves beyond cognitivist models, which might consider broad logic errors as important in mental health (such as negative processing biases, Rude et al., 2002), to understanding how a person and a space might both contribute to behavior. In the context of our opening illustration, people going to work on a high platform might perceive risk and build a handrail to create affordances of safe-to-be-on-ness in response. This process of niche construction is also active in shaping the development of traits (see Smaldino et al., 2019). A created niche can lead to constraints that fit with the perceptual experiences of the actor. For example, the bidirectional relationship between social withdrawal and social anxiety, whereby the development of a (less socially burdensome) niche protects from the negative perceptual experience of social anxiety (see Barzeva et al., 2019). However, at the same time, limiting the opportunities for the active 
perception of other people, also limits the chance for perceptual risk refinement. The process of how personality shapes niche construction helps the understanding of how both traits and situations are stable over time (Finnigan, 2020). Similarly, the perception of an environment consisting of mostly constraints will limit an individual's perceived agency, and result in individuals not redefining their niches. This is akin to the "learned helplessness" phenomenon where organisms stop trying to actively engage with the world (see Maier \& Seligman, 2016). All organisms reshape the niche in which they live, in response to the affordances and constraints of that niche, however, there is intra-species variability in tendency to do so (Laland, 2017).

Anxiousness traits, viewed through the lens of the ecological approach, are a demonstration of the variability in drive to initiate change in the environment. If starting from a heightened inclination to perceive threat from the world, then the action of "experiential avoidance" (see Chawla \& Ostafin, 2007) is satiating a base need (biological or historic-experiential). With a loop of motivated inactivity, there is no opportunity for the refinement of perceived threat affordances in the world, thus those highly Anxious individuals may construct niches which perpetuate Anxiousness behaviors. The lesson for the ecological approach, with respect to individual differences in Anxiousness, is one of recognizing the variability in which individuals consider themselves to have control over environments.

\section{4 | Future directions for the integration of ecological psychology and personality science}

It is productive to consider the merits of a Gibsonian ecological approach to personality science. Above all, personality research could do more to consider that individuals might vary due to mutualist experiences of an environment differentially soliciting behavior. We could consider personality traits as important drives for beginning a sensemaking process, which leads to motivated further exploration of opportunities in the environment. This is a move from considering that there are simple discrete categories of "person" and "environment" to considering how individuals are emergent in environments. It is the consideration of how opportunities for behavior are acted on and responded to. As described above, we could better consider psychological traits as drives for intra-species variability in the perception of affordances. Personality could be considered to initiate and perpetuate the manner with which individuals limit their perceptual refinement of the world and construct niches to suit their traits. Understanding the importance of active perception and the role of salient exploration in sensemaking also maximizes the usefulness of observational methodologies. Insight from comparative personality models is easier when the concept of perception is de-anthropomorphized. Fundamentally, in a context where other authors are encouraging novel and interesting approaches to psychometric tool development (see Mõttus et al., 2020), the role of an ecological approach to personality is to revisit core theoretical thinking. Personality research has a strong tradition in developing incrementally more useful measures, but there could be more focus on the role of theoryand we would argue mutualist, ecological theory-in terms of considering the psychology of personality. An ecological approach can work alongside existing and novel methodologies and such an approach complements practitioner thoughts and concerns in practice, but it also goes further in terms of how we might consider the theoretical mechanisms for personality.

The ecological approach to perception has not fully developed a role for personality traits in the perception of affordances, despite the recognition of individual differences in physical traits. The lack of focus on how variation in psychological traits affect perception is a curious one, since precursors of ecological psychology, such as Kurt Lewin's work in Gestalt psychology (Lewin, 1936) and William James' radical empiricism (Heft, 2001; James, 1890) were not shy of discussing the topic. For instance, Lewin (1936) defined behavior as a function of personal traits and the environments-as per his famous equation, Behavior $=f$ (Person, Environment)-and James (1890) wrote extensively about temperaments, habits, and selective perception, or the "selective industry of the mind"). Some ecological psychology researchers such as de Haan, Rietveld, Stokhof, and Denys have noted that there needs to be 
more research into "the many different ways in which the perceived environment can solicit activity" and what might lead to variance in "whether something presents itself as an attraction or rather as an "avoidance" (footnote 8, de Haan et al., 2013), but there is still yet to be a widespread use of personality in ecological psychology work. Indeed, further interaction between the individual differences (Smaldino et al., 2019) and agent-based (Kaaronen \& Strelkovskii, 2020) computational modeling techniques for examining how an agent interacts with an environment are useful for formalizing theory in this area. It would be fruitful for research in affordances to consider the influences of psychological traits as explaining variance in complex affordances.

For personality psychology, the ecological approach can be used to explain both general trait stability and potential change over time, as traits (with biological bases) drive behavior which, in turn, shape the detection of information, which refine traits. Further, considering personality traits as variability in the style and extent to which individuals seek information from the world, allows for broad cross-theory and cross-species conversations. Whilst we include discussion of two broad trait dimensions, there is promise for understanding more specific traits using ecological frameworks, such as increasing interest in human social thermoregulation traits, where social affiliation is related to homeostatic needs of individuals (see IJzerman et al., 2015). Moreover, there is increasing interest in exploring the role of personality across environments with "ecological momentary assessment" tools (e.g., Mey et al., 2020; Wilson et al., 2017) and there is productive scope in considering ways in which traits in contexts could be understood as dynamic perception-action processes.

\section{ACKNOWLEDGMENTS}

We would like to thank the editor and reviewers for their patience and assistance with improving this paper.

\section{ORCID}

Liam Paul Satchell (D) https://orcid.org/0000-0002-8805-4884

Roope Oskari Kaaronen (D) https://orcid.org/0000-0002-2414-6974

Robert D. Latzman (D) https://orcid.org/0000-0002-1175-8090

\section{REFERENCES}

Ashton, M., \& Lee, K. (2009). The HEXACO-60: A short measure of the major dimensions of personality. Journal of Personality Assessment, 91(4), 340-345. https://doi.org/10.1080/00223890902935878

Back, M. D., \& Egloff, B. (2009). Discussion on 'personality psychology as a truly behavioral science' by R. Michael Furr: Yes we can! A plea for direct behavioural observation in personality research. European Journal of Personality, 23(5), 403-408. https://doi.org/10.1002/per.725

Bancroft, J., Janssen, E., Carnes, L., Goodrich, D., Strong, D., \& Long, J. S. (2004). Sexual activity and risk taking in young heterosexual men: The relevance of sexual arousability, mood, and sensation seeking. The Journal of Sex Research, 41(2), 181-192. https://doi.org/10.1080/00224490409552226

Baron, R. M., \& Boudreau, L. A. (1987). An ecological perspective on integrating personality and social psychology. Journal of Personality and Social Psychology, 53(6), 1222-1228. https://doi.org/10.1037/0022-3514.53.6.1222

Barzeva, S. A., Richards, J. S., Meeus, W. H. J., \& Oldehinkel, A. J. (2019). The social withdrawal and social anxiety feedback loop and the role of peer victimization and acceptance in the pathways. Development and Psychopathology, 1-16. https://doi.org/10.1017/S0954579419001354

Bennett, P. C., Rutter, N. J., Woodhead, J. K., \& Howell, T. J. (2017). Assessment of domestic cat personality, as perceived by 416 owners, suggests six dimensions. Behavioural Processes, 141, 273-283. https://doi.org/10.1016/j.beproc.2017.02.020

Boomsma, D. I., Helmer, Q., Nieuwboer, H. A., Hottenga, J. J., de Moor, M. H., van den Berg, S. M., Davies, G. E., Vink, J. M., Schouten, M. J., Dolan, C. V., Willemsen, G., Bartels, M., van Beijsterveldt, T. C. E. M., Ligthart, L., \& de Geus, E. J. (2018). An extended twin-pedigree study of neuroticism in The Netherlands twin register. Behavior Genetics, 48(1), 1-11. https://doi.org/10.1007/s10519-017-9872-0

Brandes, C. M., \& Tackett, J. L. (2019). Contextualizing neuroticism in the hierarchical taxonomy of psychopathology. Journal of Research in Personality, 81, 238-245. https://doi.org/10.1016/j.jrp.2019.06.007

Brown, T. A. (2007). Temporal course and structural relationships among dimensions of temperament and DSM-IV anxiety and mood disorder constructs. Journal of Abnormal Psychology, 116(2), 313-328. https://doi.org/10.1037/0021-843X. 116.2.313 
Carlstead, K., Mellen, J., \& Kleiman, D. G. (1999). Black rhinoceros (Diceros bicornis) in U.S. Zoos: I. individual behavior profiles and their relationship to breeding success. Zoo Biology, 18(1), 17-34. https://doi.org/10.1002/(SICI)10982361(1999)18:1<17::AID-ZOO4>3.0.CO;2-K

Cattell, R. B. (1973). Personality and mood by questionnaire. Jossey-Bass.

Chawla, N., \& Ostafin, B. (2007). Experiential avoidance as a functional dimensional approach to psychopathology: An empirical review. Journal of Clinical Psychology, 63(9), 871-890. https://doi.org/10.1002/jclp.20400

Chemero, A. (2003). An outline of a theory of affordances. Ecological Psychology, 15(2), 181-195. https://doi.org/10.1207/ S15326969ECO1502_5

Corr, P. J. (2004). Reinforcement sensitivity theory and personality. Neuroscience \& Biobehavioral Reviews, 28(3), 317-332. https://doi.org/10.1016/j.neubiorev.2004.01.005

Costall, A. (2017). 1966 and all that: James Gibson and bottom-down theory. Ecological Psychology, 29(3), 221-230. https:// doi.org/10.1080/10407413.2017.1330121

de Haan, S., Rietveld, E., Stokhof, M., \& Denys, D. (2013). The phenomenology of deep brain stimulation-induced changes in OCD: An enactive affordance-based model. Frontiers in Human Neuroscience, 7. https://doi.org/10.3389/fnhum.2013. 00653

de Vries, R. E., de Vries, A., \& Feij, J. A. (2009). Sensation seeking, risk-taking, and the HEXACO model of personality. Personality and Individual Differences, 47(6), 536-540. https://doi.org/10.1016/j.paid.2009.05.029

Denissen, J. J. A., \& Penke, L. (2008). Motivational individual reaction norms underlying the Five-Factor model of personality: First steps towards a theory-based conceptual framework. Journal of Research in Personality, 42(5), 1285-1302. https://doi.org/10.1016/j.jrp.2008.04.002

DeYoung, C. G. (2010). Personality neuroscience and the biology of traits. Social and Personality Psychology Compass, 4(12), 1165-1180. https://doi.org/10.1111/j.1751-9004.2010.00327.x

Elliot, A. J. (2006). The hierarchical model of approach-avoidance motivation. Motivation and Emotion, 30(2), 111-116. https://doi.org/10.1007/s11031-006-9028-7

Exnerová, A., Svádová, K. H., Fučíková, E., Drent, P., \& Štys, P. (2010). Personality matters: Individual variation in reactions of naive bird predators to aposematic prey. Proc. R. Soc. B., 277(1682), 723-728. https://doi.org/10.1098/rspb. 2009.1673

Eysenck, S. B. G., \& Eysenck, H. J. (1978). Impulsiveness and venturesomeness: Their position in a dimensional System of personality description. Psychological Reports, 43(3_suppl), 1247-1255. https://doi.org/10.2466/pr0.1978.43.3f.1247

Finger, J. S., Dhellemmes, F., Guttridge, T. L., Kurvers, R. H. J. M., Gruber, S. H., \& Krause, J. (2016). Rate of movement of juvenile lemon sharks in a novel open field, are we measuring activity or reaction to novelty? Animal Behaviour, 116, 75-82. https://doi.org/10.1016/j.anbehav.2016.03.032

Finnigan, K. M. (2020). The stability of daily situation experiences. https://doi.org/10.31237/osf.io/ghpze

Fleeson, W. (2004). Moving personality beyond the person-situation debate. Current Directions in Psychological Science, 13(2), 83-87. https://doi.org/10.1111/j.0963-7214.2004.00280.x

Furr, R. M. (2009). Personality psychology as a truly behavioural science. European Journal of Personality, 23(5), 369-401. https://doi.org/10.1002/per.724

Gibson, E. J., \& Walk, R. D. (1996). Walking off a cliff. In P. Banyard \& A. Grayson (Eds.), Introducing psychological research (pp. 319-323). Macmillan Education UK. https://doi.org/10.1007/978-1-349-24483-6_48

Gibson, J. J. (1966). The senses considered as perceptual systems. Greenwood Press.

Gibson, J. J. (1979). The ecological approach to visual perception (17th pr). Psychology Press.

Gomez, R., \& Corr, P. J. (2010). Attention-deficit/hyperactivity disorder symptoms: Associations with Gray's and Tellegen's models of personality. Personality and Individual Differences, 49(8), 902-906. https://doi.org/10.1016/j.paid. 2010.06.033

Gosling, S. D., \& John, O. P. (1999). Personality dimensions in nonhuman animals. Current Directions in Psychological Science, 8(3), 69-75. https://doi.org/10.1111/1467-8721.00017

Graham, E. K., Weston, S. J., Gerstorf, D., Yoneda, T. B., Booth, T., Beam, C. R., Petkus, A. J., Drewelies, J., Hall, A. N., Bastarache, E. D., Estabrook, R., Katz, M. J., Turiano, N. A., Lindenberger, U., Smith, J., Wagner, G. G., Pedersen, N. L., Allemand, M., Spiro, A., ..., Deeg, D. J. H., Johansson, B., Piccinin, A. M., Lipton, R. B., Schaie, K. W., Willis, S., Reynolds, C. A., Deary, I. J., Hofer, S. M., \& Mroczek, D. K. (2020). Trajectories of big five personality traits: A coordinated analysis of 16 longitudinal samples. European Journal of Personality, 34(3), 301-321. https://doi.org/10.1002/per.2259

Gray, J. A. (1970). The psychophysiological basis of introversion-extraversion. Behaviour Research and Therapy, 8(3), 249-266. https://doi.org/10.1016/0005-7967(70)90069-0

Grzeczkowski, L., Clarke, A. M., Francis, G., Mast, F. W., \& Herzog, M. H. (2017). About individual differences in vision. Vision Research, 141, 282-292. https://doi.org/10.1016/j.visres.2016.10.006

Gyuris, E., Feró, O., \& Barta, Z. (2012). Personality traits across ontogeny in firebugs, Pyrrhocoris apterus. Animal Behaviour, 84(1), 103-109. https://doi.org/10.1016/j.anbehav.2012.04.014 
Harper, C. A., Satchell, L. P., Fido, D., \& Latzman, R. D. (2020). Functional fear predicts public health compliance in the COVID-19 pandemic. International Journal of Mental Health and Addiction. https://doi.org/10.1007/s11469-02000281-5

Heft, H. (2001). Ecological psychology in context: James Gibson, Roger Barker, and the legacy of William James's radical empiricism. L. Erlbaum.

Hensley, N. M., Cook, T. C., Lang, M., Petelle, M. B., \& Blumstein, D. T. (2012). Personality and habitat segregation in giant sea anemones (Condylactis gigantea). Journal of Experimental Marine Biology and Ecology, 426-427, 1-4. https://doi. org/10.1016/j.jembe.2012.05.011

Hittner, J. B., \& Swickert, R. (2006). Sensation seeking and alcohol use: A meta-analytic review. Addictive Behaviors, 31(8), 1383-1401. https://doi.org/10.1016/j.addbeh.2005.11.004

IJzerman, H., Coan, J. A., Wagemans, F. M. A., Missler, M. A., Beest, I. van, Lindenberg, S., \& Tops, M. (2015). A theory of social thermoregulation in human primates. Frontiers in Psychology, 6. https://doi.org/10.3389/fpsyg.2015.00464

Jacques-Hamilton, R., Hall, M. L., Buttemer, W. A., Matson, K. D., Gonçalves da Silva, A., Mulder, R. A., \& Peters, A. (2017). Personality and innate immune defenses in a wild bird: Evidence for the pace-of-life hypothesis. Hormones and Behavior, 88, 31-40. https://doi.org/10.1016/j.yhbeh.2016.09.005

James, W. (1890). The principles of psychology. Holt.

Jani, D. (2014). Big five personality factors and travel curiosity: Are they related? Anatolia, 25(3), 444-456. https://doi.org/ 10.1080/13032917.2014.909366

Kaaronen, R. O., \& Strelkovskii, N. (2020). Cultural evolution of sustainable behaviors: Pro-environmental tipping points in an agent-based model. One Earth, 2(1), 85-97. https://doi.org/10.1016/j.oneear.2020.01.003

Kennedy, J. M., Green, C. D., Nicholls, A., \& Liu, C. H. (1992). Illusions and knowing what is real. Ecological Psychology, 4(3), 153-172. https://doi.org/10.1207/s15326969eco0403_2

Kenrick, D. T., \& Funder, D. C. (1988). Profiting from controversy: Lessons from the person-situation debate. American Psychologist, 43(1), 23-34. https://doi.org/10.1037/0003-066X.43.1.23

Klinteberg, B. A., Schalling, D., \& Magnusson, D. (1990). Childhood behaviour and adult personality in male and female subjects. European Journal of Personality, 4(1), 57-71. https://doi.org/10.1002/per.2410040105

Koswara, R., Widyanti, A., \& Park, J. (2020). The role of HEXACO personality in perceived time load. Timing \& Time Perception, 8(1), 55-65. https://doi.org/10.1163/22134468-20191168

Kralj-Fišer, S., \& Schuett, W. (2014). Studying personality variation in invertebrates: Why bother? Animal Behaviour, 91 , 41-52. https://doi.org/10.1016/j.anbehav.2014.02.016

Laland, K. N. (2017). Darwin`s unfinished symphony: How culture explains the evolution of the human mind. Princeton University Press.

Latzman, R. D., Drislane, L. E., Hecht, L. K., Brislin, S. J., Patrick, C. J., Lilienfeld, S. O., Freeman, H. J., Schapiro, S. J., \& Hopkins, W. D. (2016). A chimpanzee (Pan troglodytes) model of triarchic psychopathy constructs. Clinical Psychological Science, 4(1), 50-66. https://doi.org/10.1177/2167702615568989

Latzman, R. D., Freeman, H. D., Schapiro, S. J., \& Hopkins, W. D. (2015). The contribution of genetics and early rearing experiences to hierarchical personality dimensions in chimpanzees (Pan troglodytes). Journal of Personality and Social Psychology, 109(5), 889-900. https://doi.org/10.1037/pspp0000040

Latzman, R. D., Green, L. M., \& Fernandes, M. A. (2017). The importance of chimpanzee personality research to understanding processes associated with human mental health. International Journal of Comparative Psychology, 30.

Lee, W. E., Wadsworth, M. E. J., \& Hotopf, M. (2006). The protective role of trait anxiety: A longitudinal cohort study. Psychological Medicine, 36(3), 345-351. https://doi.org/10.1017/S0033291705006847

Lewin, K. (1936). Principles of topological psychology. McGraw-Hill.

Li, C.-Y., \& Tsai, B.-K. (2013). Impact of extraversion and sensation seeking on international tourism choices. Social Behavior and Personality, 41(2), 327-333. https://doi.org/10.2224/sbp.2013.41.2.327

Lüdtke, O., Roberts, B. W., Trautwein, U., \& Nagy, G. (2011). A random walk down university avenue: Life paths, life events, and personality trait change at the transition to university life. Journal of Personality and Social Psychology, 101(3), 620-637. https://doi.org/10.1037/a0023743

Magidson, J. F., Roberts, B. W., Collado-Rodriguez, A., \& Lejuez, C. W. (2014). Theory-driven intervention for changing personality: Expectancy value theory, behavioral activation, and conscientiousness. Developmental Psychology, 50(5), 1442-1450. https://doi.org/10.1037/a0030583

Maier, S. F., \& Seligman, M. E. P. (2016). Learned helplessness at fifty: Insights from neuroscience. Psychological Review, 123(4), 349-367. https://doi.org/10.1037/rev0000033

Markon, K. E. (2009). Hierarchies in the structure of personality traits. Social and Personality Psychology Compass, 3(5), 812-826. https://doi.org/10.1111/j.1751-9004.2009.00213.x

Matthews, G. (1987). Personality and multidimensional arousal: A study of two dimensions of extraversion. Personality and Individual Differences, 8(1), 9-16. https://doi.org/10.1016/0191-8869(87)90005-5 
McCrae, R. R., \& Costa, P. T. (1987). Validation of the five-factor model of personality across instruments and observers. Journal of Personality and Social Psychology, 52(1), 81-90. https://doi.org/10.1037/0022-3514.52.1.81

Mehlhorn, K., Newell, B. R., Todd, P. M., Lee, M. D., Morgan, K., Braithwaite, V. A., Hausmann, D., Fiedler, K., \& Gonzalez, C. (2015). Unpacking the exploration-exploitation tradeoff: A synthesis of human and animal literatures. Decision, 2(3), 191-215. https://doi.org/10.1037/dec0000033

Menzies, A. K., Timonin, M. E., McGuire, L. P., \& Willis, C. K. R. (2013). Personality variation in Little Brown bats. PLoS ONE, 8(11), e80230. https://doi.org/10.1371/journal.pone.0080230

Mey, L. K., Chmitorz, A., Kurth, K., Wenzel, M., Kalisch, R., Tüscher, O., \& Kubiak, T. (2020). Increases of negative affect following daily hassles are not moderated by neuroticism: An ecological momentary assessment study Stress and Health. 36(5), 615-628. https://doi.org/10.1002/smi.2964

Morris, P. H., \& Warne, A. (2017). Personality affects 'fidgeting' in the laboratory: Implications for experimental design. Personality and Individual Differences. 118, 7-10. https://doi.org/10.1016/j.paid.2017.04.023

Mõttus, R., Wood, D., Condon, D. M., Back, M., Baumert, A., Costantini, G., Epskamp, S., Greiff, S., Johnson, W., Lukaszewski, A., Murray, A. L., Revelle, W., Wright, A. G. C., Yarkoni, T., Ziegler, M., \& Zimmermann, J. (2020). Descriptive, predictive and explanatory personality research: Different goals, different approaches, but a shared need to move beyond the Big Few traits. PsyArXiv https://doi.org/10.31234/osf.io/hvk5p

Nagel, T. (1974). What is it like to be a bat? The Philosophical Review, 83(4), 435. https://doi.org/10.2307/2183914

Norman, D. A. (1988). The psychology of everyday things. Basic Books.

Otto, K., \& Dalbert, C. (2012). Individual differences in job-related relocation readiness. Career Development International, 17(2), 168-186. https://doi.org/10.1108/13620431211225340

Piotti, P., Satchell, L. P., \& Lockhart, T. S. (2018). Impulsivity and behaviour problems in dogs: A reinforcement sensitivity theory perspective. Behavioural Processes, 151, 104-110. https://doi.org/10.1016/j.beproc.2018.03.012

Pratt, T. C., \& Cullen, F. T. (2000). The empirical status of Gottfredson and Hirschi's general theory of crime: A metaanalysis. Criminology, 38(3), 931-964. https://doi.org/10.1111/j.1745-9125.2000.tb00911.x

Rammsayer, T. H. (1997). On the relationship between personality and time estimation. Personality and Individual Differences, 23(5), 739-744. https://doi.org/10.1016/S0191-8869(97)00117-7

Reed, E. (1996). Encountering the world: Toward an ecological psychology. Oxford University Press.

Revelle, W., \& Condon, D. M. (2015). A model for personality at three levels. Journal of Research in Personality, 56, 70-81. https://doi.org/10.1016/j.jrp.2014.12.006

Roberts, B. W., Luo, J., Briley, D. A., Chow, P. I., Su, R., \& Hill, P. L. (2017). A systematic review of personality trait change through intervention. Psychological Bulletin, 143(2), 117-141. https://doi.org/10.1037/bul0000088

Rude, S. S., Wenzlaff, R. M., Gibbs, B., Vane, J., \& Whitney, T. (2002). Negative processing biases predict subsequent depressive symptoms. Cognition \& Emotion, 16(3), 423-440. https://doi.org/10.1080/02699930143000554

Satchell, L. P., Bacon, A. M., Firth, J. L., \& Corr, P. J. (2018). Risk as reward: Reinforcement sensitivity theory and psychopathic personality perspectives on everyday risk-taking. Personality and Individual Differences, 128, $162-169$. https://doi.org/10.1016/j.paid.2018.02.039

Sauer-Zavala, S., Wilner, J. G., \& Barlow, D. H. (2017). Addressing neuroticism in psychological treatment. Personality Disorders: Theory, Research, and Treatment, 8(3), 191-198. https://doi.org/10.1037/per0000224

Sinn, D. L., Gosling, S. D., \& Moltschaniwskyj, N. A. (2008). Development of shy/bold behaviour in squid: Context-specific phenotypes associated with developmental plasticity. Animal Behaviour, 75(2), 433-442. https://doi.org/10.1016/j. anbehav.2007.05.008

Sinn, D. L., Perrin, N. A., Mather, J. A., \& Anderson, R. C. (2001). Early temperamental traits in an octopus (Octopus bimaculoides). Journal of Comparative Psychology, 115(4), 351-364. https://doi.org/10.1037/0735-7036.115.4.351

Smaldino, P. E., Lukaszewski, A., von Rueden, C., \& Gurven, M. (2019). Niche diversity can explain cross-cultural differences in personality structure. Nature Human Behaviour, 3(12), 1276-1283. https://doi.org/10.1038/s41562-019-0730-3

Soto, C. J. (2019). How replicable are links between personality traits and consequential life outcomes? The life outcomes of personality replication project. Psychological Science, 30(5), 711-727. https://doi.org/10.1177/0956797619831612

Sweeney, K., Cusack, B., Armagost, F., O’Brien, T., Keiser, C. N., \& Pruitt, J. N. (2013). Predator and prey activity levels jointly influence the outcome of long-term foraging bouts. Behavioral Ecology, 24(5), 1205-1210. https://doi.org/10. 1093/beheco/art052

Tellegen, A. (1985). Structures of mood and personality and their relevance to assessing anxiety, with an emphasis on self-report. In Anxiety and the anxiety disorders (pp. 681-706). Lawrence Erlbaum Associates, Inc.

Tremmel, M., \& Müller, C. (2013). Insect personality depends on environmental conditions. Behavioral Ecology, 24(2), 386-392. https://doi.org/10.1093/beheco/ars175

Van den Bergh, O., Brosschot, J. F., Critchley, Hu, Thayer, J. F., \& Ottaviani, C. (2020). Better safe than sorry: A common signature of general vulnerability for psychopathology [Preprint]. Open Science Framework. https://doi.org/10.31219/osf. io/8ev4u 
Warren, W. H. (1984). Perceiving affordances: Visual guidance of stair climbing. Journal of Experimental Psychology: Human Perception and Performance, 10(5), 683-703. https://doi.org/10.1037/0096-1523.10.5.683

Weiss, A. (2018). Personality traits: A view from the animal kingdom. Journal of Personality, 86(1), 12-22. https://doi.org/10. 1111/jopy.12310

Wilson, R. E., Thompson, R. J., \& Vazire, S. (2017). Are fluctuations in personality states more than fluctuations in affect? Journal of Research in Personality, 69, 110-123. https://doi.org/10.1016/j.jrp.2016.06.006

Wright, H. F., Mills, D. S., \& Pollux, P. M. J. (2012). Behavioural and physiological correlates of impulsivity in the domestic dog (Canis familiaris). Physiology \& Behavior, 105(3), 676-682. https://doi.org/10.1016/j.physbeh.2011.09.019

Zuckerman, M. (1994). Behavioral expressions and biosocial bases of sensation seeking. Cambridge University Press.

Zuckerman, M. (2005). The neurobiology of impulsive sensation seeking: Genetics, brain physiology, biochemistry, and neurology. In C. Stough (Ed.), Neurobiology of exceptionality (pp. 31-52). Springer US. https://doi.org/10.1007/0-30648649-0_2

\section{AUTHOR BIOGRAPHIES}

Liam P Satchell is a lecturer in the Department of Psychology at the University of Winchester, United Kingdom. He works on the integration of ecological psychology, individual differences, and social behavior from a critical methodology perspective. His research is motivated by improving theoretical and applied (such as forensic, education, animal welfare, and sport) psychology.

Roope O. Kaaronen is a doctoral candidate at the University of Helsinki, Finland. His research interests broadly include applying ecological psychology and affordance theory to collective behavior change, with a focus on the cultural evolution of sustainable behaviors.

Robert D. Latzman is an associate professor in the Department of Psychology at Georgia State University, Atlanta, United States. His research interests fall at the intersection of developmental psychopathology, clinical neuroscience, and personality psychology. Specifically, using both human and nonhuman primate samples, his program of research aims to characterize neurobehavioral mechanisms that underlie the development and persistence of psychopathological behaviors.

How to cite this article: Satchell LP, Kaaronen RO, Latzman RD. An ecological approach to personality: Psychological traits as drivers and consequences of active perception. Soc Personal Psychol Compass. 2021;15:e12595. https://doi.org/10.1111/spc3.12595 